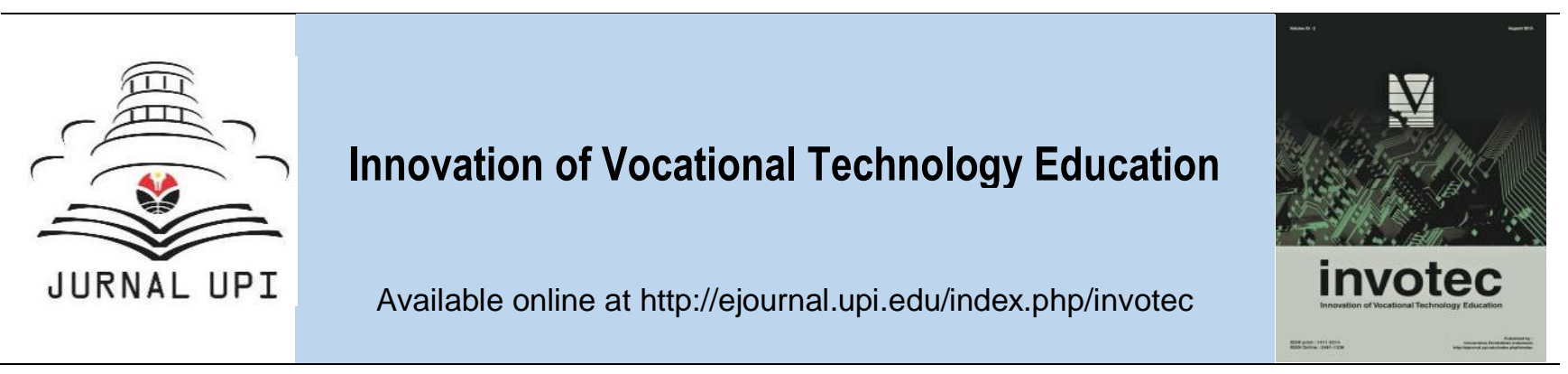

\title{
Study of the Level of Understanding of Parents towards Their Children Curriculum in Vocational Schools
}

\author{
Aris Sunawar \\ Universitas Negeri Jakarta, Indonesia
}

\section{ARTICLE INFO}

\section{Article history:}

Received 9 March 2017

Received in revised form 31

March 2017

Accepted 21 April 2017

Available online 31 August 2017

Keywords:

level of understanding, perception of parents, curriculum development

Corresponding author: sunawar@gmail.com
A B S T R A C T

The family is the smallest part in the education unit, the role of parents as educators of children is not stopped just when children start to school and handed over all their children to school education. While the curriculum in 2013, which is based morals, that assessment is not just a numbers, but also the record of the school to the child's progress. To find out how much parents knowledge of the curriculum that is being taken by their child, more research needs to be done, one method is a survey to the parents whose children are still at the high school / vocational randomly either public or private. Questions in the survey is the essence and purpose of the curriculum and the extent to which parents learn and understand the principle of the curriculum as well as participation in their children's education during school. From the results obtained that $83 \%$ of parents claimed to already know the competencies that will be owned by his son, and $80 \%$ of them have a desire to participate in curriculum development of their children. One of the obstacles they are to participate in the development is the time and their competence in curriculum development. So if parents can also be involved in the curriculum development should been socialized continuously from the school authorities and parents . Who are willing to help the development of the curriculum to get the formula of what competency is needed most and ready to work after graduation.

\section{Introduction}

Every parent wants the best for their children, with education and expertise, future children will be able to get a job easier and easier to earn money, as well as the intent of the parents to have their children in vocational schools is that children will be able to directly work to support each other's lives and have expertise later after they graduate from school. Most parents understand that education is important, but only a few are trying to follow the development of their children's education, most assume that education in schools is the responsibility of teachers and schools, while parents just play 
a role in education at home and relinquish all responsibility to the teachers, it is not appropriate for the schooling parents still have an important role in developing their competencies (Okocha, 2009).

To achieve the educational goals required an educational guideline called the curriculum, which according to Minister of Education and Culture Regulation No. 70/2003 that the curriculum is a set of plans and arrangements regarding the objectives, content and learning materials as well as the means used to guide the implementation of learning activities to achieve specific educational objectives, then it is definitely secondary vocational schools have a curriculum to achieve these objectives. The curriculum in Indonesia today is the curriculum 2013, it required the interaction thoroughly between teachers and students so that learning is not just one direction only from teacher, but also students are actively to apply what they learn in school to community. Here the role of parents as a bridge students and the community is very important, future parents who will guide their children to learn at home in accordance with the existing curriculum (Olibie, 2014).

The curriculum is a set of documents designed to serve as guidelines learning activities to achieve certain objectives, in accordance with the core competencies and competency standards are to be developed in the education unit level. Preparation of the vocational subjects should be tailored to the circumstances and capabilities of each level of education in the implementation of the education and future employment needs. So that for each unit of vocational education will be different contents of the subject area because a lot of adjusting to the circumstances and needs of the location of the graduates.

One of the formulas used to develop a curriculum that the curriculum should have suitability that consists of two things. First, the agreement between the curriculum with the demands, needs, conditions and development of society. Second, the conformity between the components of the curriculum, which is in accordance with the purpose, the process according to the content and objectives, as well as in accordance with the evaluation process, content and curriculum goals. (Despotović, et.al. 2004).

Curriculum objectives are formulated based on the development of the demands, needs and conditions of the community, and also based on the thoughts and focused on achieving philosophical values (Yulianti, 2015). Curriculum goals formulated by considering several factors:

- National Education Goals, for this purpose the foundation for every institution.

- Alignment between curriculum goals and objectives of the institution.

- Compliance objectives of the curriculum to the needs of the community or employment.

- Alignment of interest the development of science and technology.

- Alignment of curriculum objectives with the value system in society.

Vocational High School (SMK) organizes education and training programs tailored to the needs of employment. Coverage of the material being taught in vocational presented in the form of various competencies considered important and necessary for students to live a life in accordance with the demands of the working world that is packaged in a wide range of training and are grouped into three groups of programs: normative, adaptive and productive. The development of vocational curriculum with emphasis on the attainment of competency-based thinking attitudes, skills and knowledge.

The characteristic most basic curriculum in 2013 demanding the ability of teachers knowledgeable and find out as much knowledge as students today and in the future will be easy to find information freely through the development of technology and information. Students are encouraged to have more responsibility to the environment, interpersonal skills, interpersonal, and have the ability to think critically. The curriculum was developed with the aim to form the generation of productive, creative, innovative, and affective. Readiness of the teacher plays an important role in the implementation of this curriculum. Readiness of teachers will affect the activities of teachers applying scientific learning model (scientific learning) with the observation, question, reason, and communicate in the learning process.

The role of parents in children's education is very large, they have a key to the success of the child reaches the desired level of competence. For that parents can also play an active role in developing the curriculum, they can participate in the preparation of the curriculum. However, in setting the curriculum may not all parents can participate, it is limited to a few people enough time and have an adequate background to participate develop curriculum of the school. Then, in the implementation of the curriculum required a very close collaboration between the teacher and the 
parents. Most of the learning activities required curriculum implemented at home. And parents to follow or observe the activities of their children learn at home by referring to the existing curriculum.

Curriculum development is a routine activity conducted to ensure the curriculum used in the education unit is in conformity with the needs of learners and the development of the world, in curriculum development, a common way is teachers act as developers and students as recipients (Patankar \& Jadhav, 2013) but as it is known that not all teachers are competent to develop the curriculum (Castañeda and Paz, 2013) that need to be made an additional opinion of other parties, namely the parent to help formulate the curriculum development.

\section{Method}

A descriptive survey design used in this study. The design was used because it is useful is useful to analyze the perception of parents and get the data that their understanding of the school. This allows researchers to collect data from parents to identify their perceptions of involvement implementation of the curriculum in the schools their children.

Samples are parents of class X, XI and XII is obtained randomly from secondary vocational schools, schools can be either public schools or private in the region of Jakarta, in one school there can be two or more samples of each class and the sample was not determined whether the man male or female, all vocational majors into the sample undifferentiated.

The researcher was helped by two research assistants in administering copies of the questionnaire to the parents. They retrieved the questionnaire copies after the parents filled them via offline or online. Data collected and analyzed by google forms of online tools to determine the direct result of a survey conducted.

\section{Result and Discussion}

Table 1. Survey of parents

\begin{tabular}{|c|c|c|c|}
\hline Componens & $\begin{array}{l}\text { Yes } \\
(\%)\end{array}$ & $\begin{array}{l}\text { No } \\
(\%)\end{array}$ & $\begin{array}{l}\text { Not sure } \\
(\%)\end{array}$ \\
\hline Know competencies That will be owned by your children? & 83.3 & 8.3 & 8.3 \\
\hline Have you ever been invited by the school for socialization curriculum & 41.7 & 58.3 & 0 \\
\hline Whether parents are involved in the preparation of the curriculum? & 80 & 10 & 10 \\
\hline $\begin{array}{l}\text { The desire that your child has a particular competence that is } \\
\text { not in the curriculum }\end{array}$ & 79.2 & 20.8 & 0 \\
\hline
\end{tabular}

From the results of the survey conducted, found that most parents follow the wishes of their children to choose a school, for $83.3 \%$ of students choose their own school and only $16.7 \%$ of parents who determine school for their children.

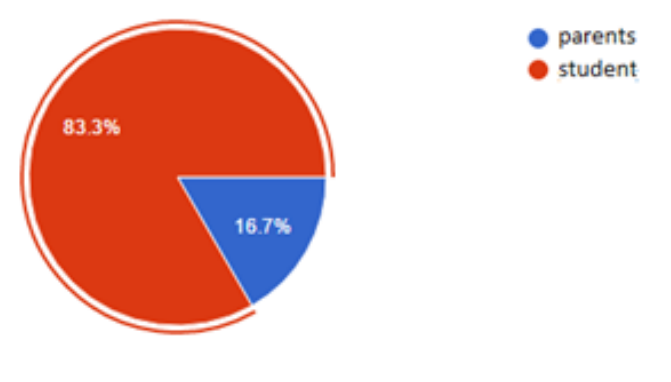

Figure 1. Whether you are choosing a school for a child or children to choose their own.

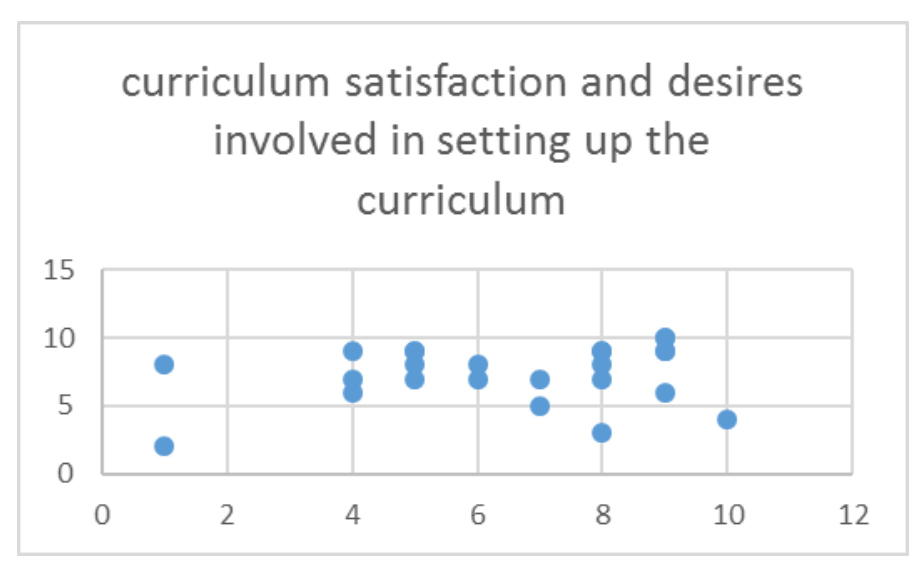

Figure 2. Curriculum satisfaction and desires involved in setting up the curriculum. 
This suggests that parents give the child the freedom to determine the schools and majors but still they are concerned with their curriculum, judging from the number of parents who want to participate and want to be involved in setting curriculum competence that is not obtained during their school children there.

Of the total respondents, $58.3 \%$ said never invited by the school to discuss their curriculum socialization and $41.7 \%$ said that they had been invited, of respondents who had been invited, they expressed less understand the curriculum studied and from which have not been invited states that $58,4 \%$ of them want to come to discuss their curriculum.

Although the dominant child to choose a school, but the parents who want to participate in developing the curriculum for children in the amount of more than $50 \%$ expressed wish to be involved in setting the curriculum and $79.2 \%$ would like to express their child to have the competencies that are not on the curriculum.

From the results of the study showed that $83.3 \%$ of parents already know the competencies that will be owned by his son, $8.3 \%$ answer don't know and $8.3 \%$ hesitate. This proves that the parents already know the curriculum followed by their children and satisfied with the structure of the existing curriculum. The level of satisfaction to the scale of 1 to $10,75 \%$ of them answered more than 7 , Which means they are already satisfied with the curriculum which is owned by his son, but the desire to be involved in the preparation of the curriculum is still large, amounting to $54.1 \%$ would participate involved in the preparation of the curriculum in schools.

\section{Conclusion}

The main obstacle parents are in involved in setting up the curriculum is the time that they are limited, nor did they have specific expertise in developing the curriculum, to help develop curriculum. That they can coordinate with schools and discuss the desire competences what they want or lessons that can be added to the curriculum of their children. Limitations of this study is the number of respondents who have not been mapped. Also have yet to take the sample data from the school. So it can be in reviewing whether the school also had tried to contact the parents to discuss with them in developing the curriculum.

\section{References}

Castañeda, L. \& Paz, P. 2013. A Curriculum Development Route Map for a Technology Enhanced Learning Era. Universal Journal of Educational Research 1(3) p. 209-20.

Despotović, Maksimović, M.I., Aleksandra \& Pejatović. 2004. Methodology of Curriculum Development in Vocational Education and Training and Adult Education.

Okocha, M. 2009. Parental Attitudes Towards Vocational Education: Implications for Counselling. Edo Journal of Counselling 2(1) p. 81-89.

Olibie, E.I. 2014. Parental Involvement in Curriculum Implementation as Perceived by Nigeria Secondary School Principals. Journal of Education and Learning 3(1) p. 40-51.

Patankar, P. \& Jadhav, M.S. 2013. Role of teachers in curriculum. in Challenges in Teacher Education, Physical Education and Sports.

Yulianti, K. 2015. The New Curriculum Implementation in Indonesia: A Study in Two Primary Schools. 9(1) p. 157-68. 